$50 \%(\mathrm{p}=0.018)$, and final tumour grade $2-3(\mathrm{p}=0.018)$. The mean follow-up was 57.8 (range 6-159) months. The five-year relapse-free survival and overall survival were 92.6\% (95\% CI: 81.3-97.2\%) and 93.5\% (95\% CI: $80.7-$ $97.9 \%)$, respectively. The rate of pregnancy was $81.1 \%(\mathrm{n}=$ $30 / 37$ ), using, in most cases, reproductive techniques $(78.4 \%)$ for this purpose.

Conclusion* Fertility-sparing management presents a high response rate in endometrial cancer. The use of LNG-IUD associates a better response rate, when compared to other treatment options. Moreover, pregnancy can be achieved with this management by use of reproductive techniques.

\section{THE IMPACT OF TUMOR SIZE ON ONCOLOGICAL OUTCOMES OF FERTILITY PRESERVATION SURGERY IN EARLY CERVICAL CANCER: A MULTI-CENTRIC STUDY BY SPAIN- GOG}

${ }^{1} \mathrm{~B}$ Gil Ibanez ${ }^{*},{ }^{2} \mathrm{~A}$ Torne, ${ }^{3} \mathrm{~A}$ Gil-Moreno, ${ }^{4} \mathrm{~A}$ Martin, ${ }^{5} \mathrm{G}$ Mancebo, ${ }^{6} \mathrm{P}$ Coronado, ${ }^{7}$ MT Marina Martín, ${ }^{8} \mathrm{~A}$ Llueca, ${ }^{2} \mathrm{~B}$ Diaz-Feijoo, ${ }^{1} \mathrm{~A}$ Tejerizo. ${ }^{1}$ Gynecological Oncology and Endoscopy Unit. Gynecology and Obstetrics Department. University Hospital 12 de Octubre. Madrid. Spain. Research Institute i+12. University Hospital 12 de Octubre., Spain; ${ }^{2}$ Unitat de Ginecologia Oncologica. ICGON. Endocrinology, Gynecology and Human Reproduction_IDIBAPS. Hospital Clínic de Barcelona., Spain; ${ }^{3} 3$ Gynecological Oncology Department, Hospital Universitari Vall d'Hebron, Universitat Autònoma de Barcelona, Barcelona, Spain. Centro de Investigación Biomédica en Red de Cáncer, CIBERONC, Madrid. , Spain; ${ }^{4}$ University Hospital Son Llàtzer. Mallorca; ${ }^{5}$ Hospital Parc de Salut Mar. Barcelona., Spain; ${ }^{6}$ Hospital Clínico. Madrid, Spain; ${ }^{7}$ Hospital La Fe. Valencia.Spain, Spain; ${ }^{8}$ Gynecology Oncology Unit Hospital General Universitario de Castellon. Departamento de Medicina. Universitat Jaume I (UJ). , Spain

\subsection{6/ijgc-2021-ESGO.243}

Introduction/Background* The combination of improved survival and delaying child bearing increases the trend of early cervical cancer diagnosis in women without a fulfilled gestational wish. Fertility preservation surgery (FSS) becomes a necessary treatment option for young women.

The aim of this study is to analyze the impact of tumor size on surgical and oncological outcomes of FSS in early cervical cancer in Spain.

Methodology A multicenter, retrospective cohort study of early cervical cancer (IA2- IB1, FIGO 2009) patients with gestational desire who underwent FSS was carried out at the departments of gynecology of 12 tertiary care hospitals between 01/2005 and 01/2019 throughout Spain. The data were registered in an on-line database. All analyses were performed using STATA 15 statistical software

Result(s)* A total of 111 patients who underwent trachelectomy were included, $82(73.9 \%)$ of them with tumors $<2$ $\mathrm{cm}$ and $29(26.1 \%)$ of them $\geq 2 \mathrm{~cm}$. Patients' characteristics were balanced except linfovascular space infiltration (LVSI). All patients were intraoperative node negative. There were no significant differences between groups regarding surgical approach, performance of a posterior cerclage, intraoperative complications or need of posterior hysterectomy.

Median follow-up was 55.7 months in patients group $<2$ $\mathrm{cm}$ tumor and 30.7 months in group $\geq 2 \mathrm{~cm}$. Eleven recurrences were diagnosed $(9.9 \%), 5(6.0 \%)$ in the $<2 \mathrm{cms}$ tumor group and $6(21.4 \%)$ in the $\geq 2 \mathrm{cms}$ tumor group $(\mathrm{p}<0.05)$.

Cox regression was performed to identify different predictor factor for recurrence. Only tumor size $(<2 \mathrm{~cm}$ vs. $\geq 2 \mathrm{cms})$ was found to be significant among histology, LVSI, previous conization or surgical approach. After adjusting for the rest of the variables, tumor size $\geq 2 \mathrm{~cm}$ has a Hazard Ratio of 5.99 (CI 95\% 1.01-35.41, $\mathrm{p}=0.036$ )

Conclusion* This study shows a real world data of a large number of trachelectomies performed in patients with early cervical cancer after negative lymphnode assessment. Selection criteria should be rigorous especially for patients with tumor $\geq 2 \mathrm{~cm}$ due to its worse oncological outcomes. Options may be discussed with the patient to reach a balance between the risk of recurrence and the best fertility results

\section{THE ADVISORY BOARD ON CANCER, INFERTILITY AND PREGNANCY}

${ }^{1 ; 2} \mathrm{~J}$ Heimovaara, ${ }^{3 ;{ }^{4} \mathrm{~K}}$ Van Calsteren, ${ }^{2} \mathrm{C}$ Lok, ${ }^{1 ; 2} \mathrm{~F}$ Amant ${ }^{*} .{ }^{1}$ Katholieke Universiteit Leuven, Department of Oncology, Leuven, Belgium; ${ }^{2}$ The Netherlands Cancer Institute (NKI), Department of Gynaecology, Amsterdam, Netherlands; ${ }^{3}$ University Hospitals Leuven, Department of Obstetrics and Gynecology, Leuven, Belgium; ${ }^{4}$ Katholieke Universiteit Leuven, Department of Development and Regeneration, Leuven, Belgium

\subsection{6/ijgc-2021-ESGO.244}

Introduction/Background* Due to the rarity of cancer during pregnancy, physicians not always have up to date knowledge on all possibilities of treatment during pregnancy. To support physicians with decision on optimal cancer treatment for their pregnant patients, the Advisory Board on Cancer, Infertility and Pregnancy (ABCIP) was founded under the umbrella of the International Network for Cancer, Infertility and Pregnancy (INCIP).

Methodology Medical experts from a variety of disciplines and countries were informed on this new initiative, and asked whether they were interested in actively participating in the ABCIP. Several national advisory boards were founded, as well as an overarching international board. Funding was acquired to build a website to facilitate accessibility for physicians requesting advice and a forum for online discussions and communication between the board members. Based on available literature, default texts were drafted to use in the recommendation letters.

Result(s)* An online platform was created at www.ab-cip.org, where physicians are able to submit questions regarding their pregnant patients with cancer, using only anonymous patient data. A total of 73 experts from a variety of disciplines and countries are joined in the national and international boards. Of this group, experts from eight countries already expressed their interest in setting up their own national advisory board. Incoming requests are discussed by the experts on a secure forum on the website. The website generates a recommendation letter, based on available literature and expert opinion of the board members, to send back to the requesting physician. In the first month after foundation, seven requests for advice were already submitted and discussed.

Conclusion* The ABCIP provides easily accessible, free of charge recommendations to physicians from all over the world with questions regarding their pregnant patients with a cancer diagnosis or patients with a cancer diagnosis who wish to become pregnant in the future. 


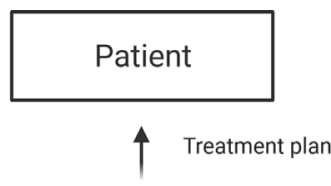

\section{Requesting physician}

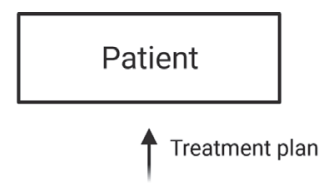

Requesting physician

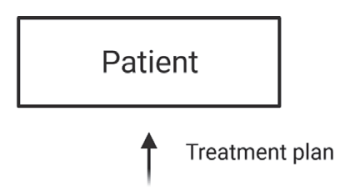

Requesting physician

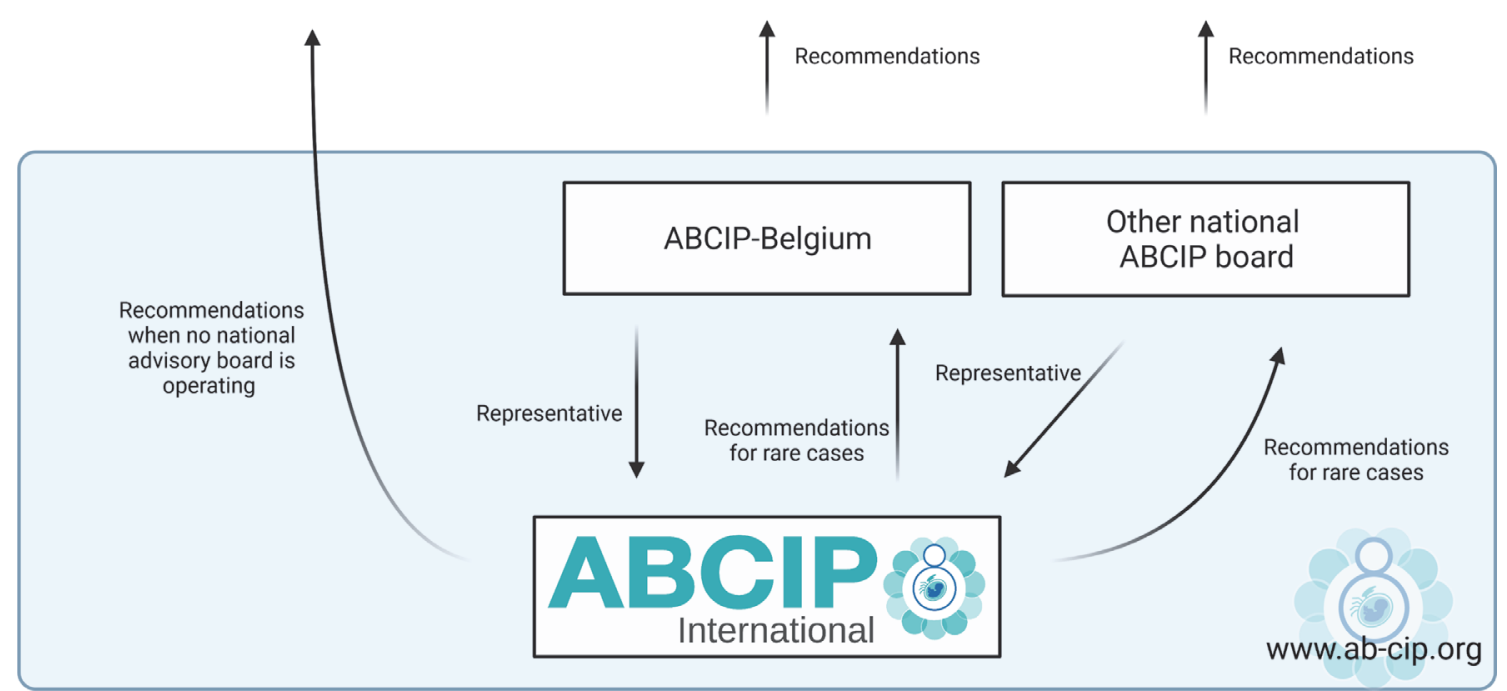

\section{Abstract 705 Figure 1}

\section{FERTILITY-SPARING AND MINIMALLY INVASIVE SURGERY IN PATIENTS WITH STAGE I MALIGNANT OVARIAN GERM CELL TUMOURS IN GERMANY}

\begin{abstract}
${ }^{1} \mathrm{M}$ Klar, ${ }^{2} \mathrm{H}$ Plett, ${ }^{2} \mathrm{P}$ Harter, ${ }^{2 ;}{ }^{3} \mathrm{~F} \mathrm{Heitz,}{ }^{4} \mathrm{~S}$ Kommoss, ${ }^{5} \mathrm{~J} \mathrm{Keul},{ }^{3} \mathrm{E}$ Roser, ${ }^{3} \mathrm{~J}$ Sehouli, ${ }^{3} \mathrm{E}$ loana Braicu, ${ }^{1} \mathrm{M}$ Bossart, ${ }^{1} \mathrm{MF}$ Hasanov, ${ }^{6} \mathrm{~B}$ Czogalla, ${ }^{6} \mathrm{~A}$ Burges, ${ }^{7} \mathrm{~T}$ Link, ${ }^{8} \mathrm{M}$ Doris, ${ }^{9} \mathrm{~A}$ Staebler, ${ }^{10} \mathrm{~L}$ Hanker, ${ }^{11} \mathrm{~A}$ Hasenburg. ${ }^{1}$ University of Freiburg, Freiburg Medical School, Department of Obstetrics and Gynaecology, Freiburg, Germany; ${ }^{2}$ Evang. Huyssens-Stiftung Essen-Huttrop (eine Einrichtung der KEM | Evang. Kliniken Essen-Mitte gGmbH), Essen, Germany; ${ }^{3}$ Charité - Universitätsmedizin Berlin, Department of Gynecology with Center for Oncological Surgery, Berlin, Germany; ${ }^{4}$ Tübingen University hospital, Department of Women's health, Tuebingen, Germany; ${ }^{5}$ Tübingen University Hospital, Obstetrics and Gynaecology, Tübingen, Germany; ${ }^{6}$ University Hospital LMU Munich Grosshardern, Obstetrics and Gynaecology, Germany; ${ }^{7}$ University Hospital of Dresden, Obstetrics and Gynaecology, Dresden, Germany; ${ }^{8}$ University Hospital of Munich, Institute of Pathology, Munich, Germany; ${ }^{9}$ University Hospital of Tuebingen, Institute of Pathology, Tuebingen, Germany; ${ }^{10}$ University Hospital Schleswig-Holstein, Obstetrics and Gynaecology, Luebeck, Germany; ${ }^{11}$ University of Mainz, Obstetrics and Gynaecology, Mainz, Germany
\end{abstract}

\subsection{6/ijgc-2021-ESGO.245}

Introduction/Background* Malignant ovarian germ cell tumours (OGCT) often affect women of younger age at an early stage of disease who may desire fertility conservation. The Arbeitsgemeinschaft fuer Gynaekologische Onkologie (AGO) has established a clinicopathological (Current Ovarian geRm cell and SEx cord stromal Tumour Treatment strategies, CORSETT) database to describe treatment strategies and outcomes for these women.

Methodology 20 German centres entered mixed retro- and prospective data of 56 FIGO stage I OGCT patients treated between 2000 to 2014 into the CORSETT database. An independent CORSETT pathology reference panel re-evaluated the primary histological diagnosis. A descriptive analysis of the treatment strategies, pregnancy rates and disease recurrence was conducted.

Result(s)* Median age at diagnosis of patients with malignant dysgerminoma, mixed OGCT and teratoma was 28 (IQR 26 - 33), $33(30$ - 40) and 38 (29 - 44) years. FIGO IA/IB/IC stage distribution was $13 / 2 / 11$ for dysgerminoma, 3/0/9 for mixed OGCT and 8/0/8 for teratoma patients. Laparoscopy was performed for 23 (69.7\%) dysgerminoma, six (35.3\%) mixed OGCT and eight (40\%) teratoma patients and fertility-sparing surgery was provided for $>80 \%$ of all FIGO I OGCT patients. Intra-operative cyst rupture occurred in six (19.4\%) dysgerminoma, five (41.6\%) mixed OGCT and four (25.5\%) teratoma patients and adjuvant chemotherapy was consequently given in one $(3.5 \%)$ dysgerminoma, nine $(81.2 \%)$ mixed OGCT and eight $(47 \%)$ teratoma patients. Four (14.3\%) dysgerminoma, three (27. 3\%) mixed OGCT and four (23.5\%) teratoma patients conceived after first line treatment. The disease reoccurred in two (7.1\%) dysgerminoma, five (45.5\%) mixed OGCT and two (11.8\%) teratoma patients, predominantly intraperitoneally. No FIGO I OGCT patient died due to disease recurrence.

Conclusion* Women with mixed OGCTs had a high risk of intra-operative cyst rupture and high recurrence rates despite FIFO stage I disease. These events had no impact though on overall survival rates. 